\title{
ANÁLISE DA POSSIBILIDADE DE REGULAÇÃo DA PUBLICIDADE COMPORTAMENTAL (BEHAVIORAL ADVERTISING) PELO MICROSSISTEMA CONSUMERISTA
}

\author{
ANALYSIS OF THE POSSIBILITY OF BEHAVIOURAL ADVERTISING \\ REGULATION BY CONSUMERIST MICROSYSTEM
}

${ }^{1}$ Fabrício Germano Alves

\section{RESUMO}

A publicidade comportamental, principalmente quando é desenvolvida online, constitui uma prática publicitária relativamente recente que, apesar de possuir alguns sinais de regulamentação no âmbito internacional, ainda não possui uma regulamentação expressa no microssistema consumerista brasileiro. O próprio Código de Defesa do Consumidor é completamente omisso em relação a esse tipo de prática. Partindo do estudo de documentos e provimentos normativos estrangeiros, conjugados com os princípios que permeiam a atividade publicitária no Brasil, o presente trabalho pretende analisar a possibilidade de regulação dessa técnica publicitária pelo microssistema consumerista brasileiro.

Palavras-chave: Publicidade comportamental, Consumidor, Regulação

\begin{abstract}
Behavioural advertising, especially when it is online developed, is a relatively new advertising practice, despite having some regulatory signs internationally, it doesn't have an express provision in the Brazilian consumerist microsystem. Even the Consumer's Protection Code is completely silent on this type of practice. From the study of foreign normative documents and provisions in conjunction with the principles that permeate the advertising activity in Brazil, this study aims to examine the possibility of regulating this advertising technique by the Brazilian consumerist microsystem.
\end{abstract}

Keywords: Behavioral advertising, Consumer, Regulation

\footnotetext{
${ }^{1}$ Doutor em Sociedad Democrática pela Universidad del Pais Vasco - EHU, Lejona (Espanha). Professor pela Universidade Federal do Rio Grande do Norte - UFRN, Rio Grande do Norte (Brasil).

E-mail: fabriciogermano@hotmail.co.uk
} 


\section{INTRODUÇÃO}

Nos dias atuais, a comunicação publicitária desempenha uma função determinante na conformação do mercado de consumo, devido principalmente ao seu poder de influência, que é capaz de direcionar a conduta do consumidor no sentido pretendido pelo fornecedoranunciante. Entretanto, em consonância com a proteção do consumidor constitucionalmente estabelecida, o desenvolvimento da atividade publicitária é regulado pelo microssistema consumerista, tanto mediante o ordenamento jurídico de origem estatal, quanto por meio do conjunto de normas éticas instituídas pelos próprios publicitários.

Atualmente, é patente a enorme quantidade de relações de consumo que são realizadas por meio da internet. Esse mesmo instrumento é utilizado também para a aplicação de algumas técnicas publicitárias, dentre as quais está a publicidade comportamental (behavioral advertising), contudo, esse tipo de prática ainda não possui uma regulamentação específica no microssistema consumerista brasileiro.

Entretanto, em razão de se tratar de uma forma de publicidade que já se mostra como uma realidade no mercado de consumo, torna-se necessário o seu estudo para que haja a identificação de critérios que possam subsidiar o seu controle tendo em vista a proteção dos consumidores.

Inicialmente, o presente texto tratará de esclarecer o conceito de publicidade em geral, adotado como parâmetro para aplicação da regulamentação presente no microssistema consumerista, para em seguida abordar o conceito da publicidade comportamental em si, fundamentando-se em apontamentos doutrinários e documentos oficiais emitidos por algumas instituições, bem como a forma de manifestação dessa técnica nas relações de consumo. Posteriormente, se buscará verificar qual o tratamento que a espécie publicitária em questão deve receber por parte do microssistema consumerista.

\section{CONCEITO DE PUBLICIDADE ADOTADO PARA FINS DE APLICAÇÃO DA REGULAMENTAÇÃO PROTETIVA DO CONSUMIDOR}

Dentro do microssistema consumerista, principalmente no Código de Proteção e Defesa do Consumidor (Lei Federal no 8.078 de 11 de setembro de 1990), existem disposições normativas limitadoras idôneas a possibilitar o controle das práticas comerciais que fazem parte do universo das relações de consumo, abrangendo o marketing, a comunicação comercial, a oferta e consequentemente a publicidade de produtos e serviços no mercado de consumo. 
Mediante essas disposições normativas se estabelece um conjunto de princípios e regras como parâmetros de conduta e diretrizes a serem seguidas por todos os que atuem nesse tipo de atividade, devendo sempre resguardar a livre concorrência e tomar por base os princípios da boa-fé objetiva, da transparência e da confiança. No entanto, para que se possa aplicar a parte desse microssistema referente à proteção e defesa do consumidor perante a publicidade nomeadamente é imprescindível que se tenha uma compreensão clara a respeito do que consiste uma prática publicitária nos termos da normatização consumerista vigente.

A publicidade é considerada um mecanismo de incitação à contratação que atua como um meio de tornar produtos e serviços conhecidos pelo maior número de pessoas possível ${ }^{1}$. A publicidade é por natureza um mecanismo de persuasão, que tem a finalidade de modificar ou simplesmente reforçar as atitudes do consumidor, influindo em suas decisões²

Trata-se de um instrumento essencial para divulgar informações aos consumidores. Quando não contém mensagens publicitárias enganosas e de conteúdo inverídico, que lesionam os direitos fundamentais dos consumidores, as informações contidas na publicidade os beneficiam, sobretudo na medida em que os permite a realização de uma seleção adequada dos produtos e serviços a serem consumidos ${ }^{3}$.

A American Marketing Association instituiu uma definição bastante abrangente de publicidade segundo a qual a classifica como a veiculação de anúncios e mensagens persuasivas, em tempos ou espaços pagos, através de qualquer meio de comunicação em massa, por empresas, organizações sem fins lucrativos, agências governamentais, e indivíduos que buscam informar e/ou persuadir membros de um mercado ou um público alvo particular, a respeito de seus produtos, serviços, organizações ou ideias ${ }^{4}$.

Para a compreensão do conceito de publicidade é possível tomar como diretriz a Diretiva 84/450/CEE de 10 de setembro de 1984 do Conselho das Comunidades Europeias, que trouxe uma definição de publicidade no artigo $2^{-}$, item 1 na qual apresenta-a como sendo qualquer forma de comunicação feita no âmbito de uma atividade comercial, industrial, artesanal ou liberal com a finalidade de promover o fornecimento de bens ou de serviços,

\footnotetext{
${ }^{1}$ REYES LÓPEZ, María José. Manual de derecho de consumo. Madrid: La Ley, 2009, p. 189.

${ }^{2}$ OLEAGA, Ricardo. Aportación consumerista a la publicidade. In: La publicidade desde el consumidor. Bizkaia: Eroski Libros, 1991, p. 84

${ }^{3}$ LEÓN ARCE, Alicia de; MORENO-LUQUE CASARIEGO, Carmen; AZA CONEJO, Ma Jesus. Derecho de consumo. Barcelona: Forum, 1995, p. 118.

${ }^{4}$ A referida definição no original é encontrada no Dicionário da American Marketing Association nos seguintes termos (Disponível em: <https://www.ama.org/resources/Pages/Dictionary.aspx>, Acesso em: 22 mar. 2014): "The placement of announcements and persuasive messages in time or space purchased in any of the mass media by business firms, nonprofit organizations, government agencies, and individuals who seek to inform and/ or persuade members of a particular target market or audience about their products, services, organizations, or ideas".
} 
incluindo os bens imóveis, os direitos e as obrigações ${ }^{5}$. Na doutrina brasileira a publicidade já foi definida como toda a informação ou comunicação difundida com a finalidade direta ou indireta de promover junto aos consumidores a aquisição de um produto ou a utilização de um serviço, independentemente do local ou meio de comunicação utilizado ${ }^{6}$.

Concomitantemente, é possível afirmar que a publicidade consiste em uma prática comercial de marketing, desenvolvida mediante uma comunicação comercial (feita através de veículos de difusão) que apresenta uma oferta destinada à divulgação, com finalidade econômica, de determinado produto, serviço, marca ou empresa, com o escopo de persuadir consumidores, direta ou indiretamente, provocando ou aumentando a demanda de um determinado produto ou serviço ou em relação a uma determinada marca ou empresa que está sendo objeto do anúncio.

De tal forma, tem-se que que são formas de publicidade as mensagens inseridas nos vários meios de comunicação utilizados pelos fornecedores para influenciar a vontade do consumidor, tais como: embalagens e rótulos de produtos, outdoors, folhetos, pôsteres, painéis, cartazes, televisão, internet, rádio, entre outros.

Existem três personagens que participam diretamente da efetivação da comunicação publicitária: o anunciante, o agente publicitário (ou agência publicitária) e o veículo de divulgação. $\mathrm{O}$ anunciante é o patrocinador da mensagem, isto é, o fornecedor que detém o produto, serviço, marca ou empresa objeto do anúncio. $\mathrm{O}$ agente publicitário ou agência publicitária é o personagem contratado pelo fornecedor-anunciante para a criação e desenvolvimento da mensagem publicitária. A Lei Federal nº 4.680 de 18 de junho de 1965 já trazia em seu texto uma definição expressa a respeito da profissão de publicitário, bem como do que consiste uma agência publicitária, em seus artigos $1^{\text {07}}$ e $3^{\text {o}}$ respectivamente. O veículo

\footnotetext{
5 Directiva 84/450/CEE. Disponível em: <http://eur-lex.europa.eu/smartapi/cgi/sga_doc?smartapi!celexapi! prod!CELEXnumdoc\&lg=PT\&numdoc=384L0450\&model=guichett $>$. Acesso em: 23 ago. 2010. A partir dessa definição Santella apresenta um conjunto de critérios que devem ser preenchidos para a caracterização de uma mensagem publicitária da seguinte maneira: “a) Forma de comunicación divulgación para dirigir la atención del público o de los medios de comunicación, cualquier forma de mensaje (radiodifundido). b) Realizada por una persona física o jurídica, pública o privada; por una empresa pública o privada. c) En el ejercicio de una actividad comercial, industrial, artesanal, o professional (liberal). d) Com el fin de promover de forma directa o indirecta (de modo mediato o inmediato) la contratación (el suministro)". SANTAELLA LÓPEZ, Manuel. El nuevo derecho de la publicidad. Madrid: Civitas, 1992, p. 50 - 51.

${ }^{6}$ MARQUES, Cláudia Lima. Contratos no código de defesa do consumidor: o novo regime das relações contratuais. 4. ed. São Paulo: Revista dos Tribunais, 2004, p. 345.

${ }^{7}$ Art. 1‥ São Publicitários aquêles que, em caráter regular e permanente, exerçam funções de natureza técnica da especialidade, nas Agências de Propaganda, nos veículos de divulgação, ou em quaisquer emprêsas nas quais se produza propaganda.

${ }^{8} \mathrm{O}$ artigo 3 o trouxe uma definição de agência publicitária como sendo “[...] pessoa jurídica [...] especializada na arte e técnica publicitária, que, através de especialistas, estuda, concebe, executa e distribui propaganda aos veículos de divulgação, por ordem e conta de clientes anunciantes, com o objetivo de promover a venda de
} 
de divulgação é o meio de comunicação social, visual ou auditivo, mediante o qual a mensagem publicitária é transmitida ao público destinatário.

O processo de criação da publicidade pode ser dividido em quatro fases distintas. Primeiramente, ocorre uma etapa que diz respeito ao repasse, feito pelo anunciante à empresa publicitária ou agente publicitário, das informações concernentes à empresa, marca, produto ou serviço que se deseja anunciar, assim como as expectativas em relação à campanha publicitária. Essa primeira fase de criação publicitária é chamada de briefing. A finalidade do briefing é propiciar o conhecimento necessário à empresa publicitária sobre o anunciante bem como sobre suas expectativas para que possa proceder a gênese da peça publicitária de acordo com as suas necessidades.

A segunda fase da criação publicitária diz respeito a uma reflexão estratégica feita dentro da agência publicitária, analisando as informações que foram fornecidas pelo fornecedoranunciante juntamente com um conjunto de ideias apresentadas pela equipe publicitária. Desta análise são escolhidas determinadas propostas e apresentadas algumas diretrizes ao anunciante patrocinador. Posteriormente, é elaborado um plano de mídia, considerando o orçamento disponível e o universo de consumidores ao qual a publicidade será destinada.

Logo após a reflexão estratégica encontra-se uma terceira fase que diz respeito à fase de criação propriamente dita da publicidade. Nesta, o agente publicitário atua com mais ênfase exercendo sua criatividade e liberdade de criação, mas sempre de maneira guiada e orientada pela diretriz escolhida pelo anunciante. É nesta fase de confecção do anúncio publicitário que deve ser feita a aferição deste com os preceitos instituídos pela Constituição Federal, a legislação infraconstitucional consumerista (principalmente o Código de Proteção e Defesa do Consumidor), assim como com o Código de Autorregulamentação Publicitária, para que se obtenha uma peça publicitária em consonância com os ditames do microssistema consumerista.

Por fim temos a fase de produção da peça publicitária em si, onde é escolhido o meio de comunicação social a ser utilizado para a veiculação da mensagem publicitária (geralmente um meio de comunicação em massa) e é feita a confecção do material a ser utilizado na campanha publicitária de acordo com o veículo de comunicação escolhido (visual e/ou auditivo), completando assim as fases de criação da publicidade.

A comunicação publicitária é vista atualmente como a mais importante técnica de estimulação ao consumo na sociedade moderna, estimulação essa que provoca vultosas

produtos e serviços, difundir idéias ou informar o público a respeito de organizações ou instituições colocadas a serviço dêsse mesmo público". 
consequências sociais, pois nem todos que são expostos a um determinado anúncio publicitário dispõem dos meios econômicos necessários para adquirir ou utilizar os produtos e/ou serviços nele anunciados. Com efeito, a situação se configura de maneira que enquanto a publicidade manda consumir a economia o proíbe, o que faz com que a ditadura da sociedade de consumo exerça um totalitarismo simétrico ao de sua irmã gêmea, a ditadura da organização desigual do mundo 9 .

Atualmente a comunicação publicitária não se destina tão somente ao repasse de informações sobre o produto e/ou serviço aos consumidores, todavia atua com o objetivo principal de orientar o consumo, criar necessidades e ampliar a demanda ${ }^{10}$. A questão principal é que a mensagem publicitária atua invadindo e influenciando a esfera decisória do consumidor, por vezes levando-o a adquirir ou utilizar certos produtos ou serviços dos quais não necessitava realmente ou mesmo sem maiores questionamentos a respeito das características ou qualidades que estes apresentam.

Constatando essa forma de atuação da publicidade na sociedade de consumo, que representa o seu vasto poder de criar hábitos e ditar comportamentos sociais, mostra-se necessária uma compreensão pormenorizada desse instituto para que sejam apropriadamente aplicadas as disposições normativas do microssistema consumerista relacionadas à publicidade em geral, bem como à publicidade comportamental, a fim de que se possa propiciar uma tutela mais efetiva do consumidor em relação essa espécie de comunicação publicitária.

No microssistema de proteção consumerista existe um conjunto de princípios e regras que permitem o controle das práticas comerciais que integram o universo das relações de consumo. Dentre elas encontram-se o marketing, a comunicação comercial e a oferta, que possui como uma das suas principais formas de manifestação a comunicação publicitária. Esta deve ser realizada de acordo com determinados parâmetros e diretrizes estabelecidas na legislação, sobretudo no Código de Defesa do Consumidor. Dentre eles se destacam: primeiramente a veracidade (artigo $37, \S 1^{\circ}$ ) e a não enganosidade ( $\operatorname{artigo} 37, \S 2^{\circ}$ ), além de outros como a livre concorrência (artigo $4^{\circ}$, inciso VI), a boa-fé objetiva (artigo $4^{\circ}$, inciso III), a transparência ${ }^{11}$ e o respeito à dignidade (artigo $4^{\circ}$, caput).

\footnotetext{
${ }^{9}$ GALEANO, Eduardo. De pernas pro ar: a escola do mundo ao avesso. Tradução de Sérgio Faraco. 9. ed. Porto Alegre: L\&PM, 2007, p. 25.

${ }^{10}$ AMARAL JÚNIOR, Alberto do. O princípio da vinculação da mensagem publicitária. In: Revista de direito do consumidor. São Paulo: Revista dos Tribunais, v. 14, 1995, p. 42.

${ }^{11}$ CUNHA, Belinda Pereira da. Antecipação da tutela no Código de Defesa do Consumidor. São Paulo: Saraiva, 1999, p. 72.
} 


\section{CONCEITO E FORMA DE MANIFESTAÇÃO DA PUBLICIDADE COMPORTAMENTAL}

A publicidade comportamental não possui regulamentação expressa no Código de Defesa do Consumidor (Lei Federal no 8.078/1990) ou mesmo na legislação complementar, contudo, para que a mesma possa ser objeto de controle no sentido de permitir uma proteção mais efetiva dos consumidores a ela expostos, é preciso identificar o seu conceito e forma de manifestação.

\subsection{CONCEITO DE PUBLICIDADE COMPORTAMENTAL}

Configura-se publicidade comportamental (behavioral advertising) ${ }^{12}$ quando o anunciante elabora a peça publicitária utilizando de técnicas de contextualização (de acordo com o conteúdo de cada página que está sendo acessada) e personalização (utilizando informações do próprio consumidor, tais como a sua posição geográfica, a sua faixa etária etc. ${ }^{13}$ ), fundamentando-se no comportamento online do consumidor.

A publicidade comportamental online constitui uma prática que consiste em direcionar anúncios publicitários específicos para determinados consumidores, de acordo com o seu comportamento online anterior ${ }^{14}$, ou seja, é destinada a um grupo, classe ou categoria de consumidores de acordo com uma base de dados a respeito dos mesmos elaborada a partir de interesses previamente demonstrados. Deste modo, os fornecedores conseguem cada vez mais alinhar seus anúncios publicitários em relação aos supostos interesses de seus destinatários ${ }^{15}$. De fato, a prática em questão consiste em uma espécie de segmentação de mercado fundamentada em um critério comportamental.

\footnotetext{
12 Prática publicitária discutida na palestra proferida pelo Chairman da Federal Trade Commission (FTC), Jon Leibowitz, no dia 12 de maio de 2010, na National Cable \& Telecomunications. Disponível em: <http://www.ftc.gov/sites/default/files/documents/public_statements/wheres-remote-maintaining-consumercontrol-age-behavioral-advertising/100512nctaspeech.pdf $>$. Acesso em: 13 fev. 2015.

${ }^{13}$ SCHERKERKEWITZ, Isso Chaitz. Direito e internet. São Paulo: Revista dos Tribunais, 2014, p. 97.

${ }^{14}$ CRANOR, Lorrie Faith. Can Users Control Online Behavioral Advertising Effectively? In: IEEE Security \& Privacy [1540-7993] Cranor, Lf, 2012 v. 10, no. 2 p. 93.

15 “'Online behavioral advertising involves the tracking of consumers' online activities in order to deliver tailored advertising. The practice, which is typically invisible to consumers, allows businesses to align their ads more closely to the inferred interests of their audience". FTC STAFF REPORT. Self-Regulatory Principles For Online Behavioral Advertising: Behavioral Advertising Tracking, Targeting, \& Technology. February 2009. Disponível em: $\quad<$ http://www.ftc.gov/sites/default/files/documents/reports/federal-trade-commission-staff-report-selfregulatory-principles-online-behavioral-advertising/p085400behavadreport.pdf $>$. Acesso em: 3 mar. 2015.
} 


\subsection{FORMA DE MANIFESTAÇÃO}

A principal forma de manifestação da publicidade comportamental é através da internet (online $)^{16}$. O ambiente virtual serve de instrumento para a criação de um verdadeiro perfil de cada consumidor (profiling) construído a partir de seus hábitos de navegação ${ }^{17}$, que possuem até mesmo valor de mercado (comercial) ${ }^{18}$, pois este encontra inúmeras vantagens em atingir os consumidores através das novas mídias ${ }^{19}$.

$\mathrm{Na}$ realidade atual os anunciantes e seus fornecedores de dados mantêm uma grande variedade informações acerca dos consumidores que os permite direcionar as mensagens publicitárias de acordo com cada tipo de media ${ }^{20}$. Nesse contexto, quanto maior a especificidade do anúncio no que diz respeito ao seu direcionamento, mais efetiva será a comunicação publicitária $^{21}$.

A publicidade geralmente se utiliza das seguintes técnicas: remarketing, ao criar anúncios de acordo com o tipo de site que é visitado pelo consumidor; personalização na rede (web personalization), ao ressaltar gostos e preferências já previamente conhecidos dos consumidores; e a personalização do negócio (deal customization), ao instigar o consumo através de descontos especificamente criados de acordo com seu perfil de navegação ${ }^{22}$.

Fundamentando-se em informações tais como faixa etária, sexo, estado civil, status social, estilo de vida, localização geográfica etc., os consumidores são classificados e os fornecedores anunciantes determinam a forma de efetivação da publicidade comportamental, elegendo, v.g., a localização de seus pontos de distribuição, onde e como devem anunciar ${ }^{23}$.

\footnotetext{
16 A publicidade comportamental é também chamada Online Behavioral Advertising (OBA) ou Publicidade Comportamental Online.

${ }^{17}$ ESCOLA NACIONAL DE DEFESA DO CONSUMIDOR (Danilo Doneda). A proteção de dados pessoais nas relações de consumo: para além da informação creditícia. Brasília: SDE/DPDC, 2010, p. 62.

${ }^{18}$ MARTÍNEZ MARTÍNEZ, Ricard. Protección de datos personales y redes sociales: un cambio de paradigma. In: RALLO LOMBARTE, Artemi; MARTÍNEZ MARTÍNEZ, Ricard (Coord.). Derecho y redes sociales. 2. ed. Navarra: Aranzadi, 2013, p. 89.

${ }^{19}$ CLINE, Kelly M.; COX, Jeffrey T. Parsing the demographic: the challenge of balancing online behavioral advertising and consumer privacy considerations. In: Journal of Internet law [1094-2904] Cox, Jeffrey, 2012 v. 15 , no. 9 , p. 3 .

20 SMITH, Mike. Targeted: how technology is revolutionizing advertising and the way companies reach consumers. New York: AMACOM, 2015, p. 113.

${ }^{21}$ Ibid., p. 113.

22 TAYLOR, Gabriela. Advertising in a digital age: best practices \& tips for paid search and social media advertising. Lexington: Global \& Digital, 2013, 46.

${ }^{23}$ CLARK, Erick. La publicidad y su poder: las técnicas de provocación al consumo. Barcelona: Planeta, 1989, p. 217.
} 


\section{REGULAÇÃO DA PUBLICIDADE COMPORTAMENTAL}

Não há dúvida de que o consumidor precisa ser protegido da captação indevida de suas informações pessoais meio de sites e cadastros, pois esse tipo de prática, quando inadvertida, configura uma espécie de captura abusiva do consumidor ${ }^{24}$. Isso pode acontecer com a finalidade de criar subsídios para a publicidade comportamental, gerando consequências nefastas tais como: a limitação das escolhas do consumidor (boxing $)^{25}$ e a instituição de preço de acordo om o perfil (adaptative pricing) ${ }^{26}$. Por isso essa espécie publicitária necessita ser regulada pelo sistema jurídico.

\subsection{NO PLANO INTERNACIONAL}

Apesar da existência da Diretiva (2002/58/EC) da União Europeia que regulamenta o processamento de dados pessoais e a proteção da privacidade no setor de comunicações eletrônicas, referindo-se à publicidade online ${ }^{27}$, sua interpretação tem sido controversa no que diz tange à publicidade comportamental ${ }^{28}$. Contudo, o Interactive Advertising Bureau (IAB) publicou um documento intitulado IAB Europe EU Framework for Online Behavioural Advertising, instituindo um conjunto de boas práticas e princípios com a finalidade de melhorar a transparência e o controle pelos consumidores ${ }^{29}$.

Nos estados Unidos, a Federal Trade Comission (FTC) já publicou documentos contendo um conjunto de princípios voltados para a autorregulamentação da publicidade comportamental online $e^{30}$, e também convocando as empresas para agirem no sentido de

\footnotetext{
${ }^{24}$ DIAS, Lucia Ancona Lopez de Magalhães. Publicidade e direito. São Paulo: Revista dos Tribunais, 2010 , p. 95.

${ }^{25}$ ABRAMS, Martin. Boxing and concepts of harm. In: Privacy and Data Security Law Journal, set. 2009, p. 673676.

${ }^{26}$ ESCOLA NACIONAL DE DEFESA DO CONSUMIDOR (Danilo Doneda), A proteção de dados pessoais nas relações de consumo: para além da informação creditícia, Brasília, SDE/DPDC, 2010, p. 69.

27 Directive 2002/58/EC. $\quad$ Disponível em: lhttp://eurlex.europa.eu/LexUriServ/LexUriServ.do?uri=CELEX:32002L0058:en:HTML>. Acesso em: 3 mar. 2015.

${ }^{28}$ TUCKER, Avi Goldfarb and Catherine E. Economic and Business Dimensions Online Advertising, Behavioral Targeting, and Privacy. In: Communications of the ACM [0001-0782] Goldfarb, A, 2011, v. 54, no. 5, p. 26.

29 IAB EUROPE. IAB Europe EU Framework for Online Behavioural Advertising. Disponível em: <http://www.iabeurope.eu/files/5013/8487/2916/2013-11-11_IAB_Europe_OBA_Framework.pdf>. Acesso em: 3 mar. 2015.

${ }^{30}$ FEDERAL TRADE COMISSION STAFF REPORT. Online Behavioral Advertising: Moving the Discussion Forward to Possible Self-Regulatory Principles. Disponível $<$ https://www.ftc.gov/sites/default/files/documents/public_statements/online-behavioral-advertising-movingdiscussion-forward-possible-self-regulatory-principles/p859900stmt.pdf>. Acesso em: 9 mar. 2015. FEDERAL TRADE COMISSION STAFF REPORT. Self-Regulatory Principles For Online Behavioral Advertising: Behavioral Advertising Tracking, Targeting, \& Technology. February 2009. Disponível em: <http://www.ftc.gov/sites/default/files/documents/reports/federal-trade-commission-staff-report-self-regulatoryprinciples-online-behavioral-advertising/p085400behavadreport.pdf $>$. Acesso em: 3 mar. 2015
} 
implementar as melhores práticas no que diz respeito à proteção das informações privadas dos consumidores, de maneira a permitir um maior controle pelo consumidor da coleta e uso de seus dados pessoais, simplificando suas escolhas e aumentando a transparência ${ }^{31}$.

A finalidade das diretivas instituídas pela FTC é propiciar aos consumidores a percepção do fato de estarem sendo alvo de publicidade comportamental, bem como o direito de escolher se seus dados e/ou histórico de navegação poderão ou não ser utilizados para subsidiar esse tipo de prática publicitária. Assim, quando existir a possibilidade de escolha, os agentes deverão tomar todas as providências necessárias para que a escolha realizada pelo consumidor seja respeitada ${ }^{32}$.

\subsection{NO MICROSSISTEMA CONSUMERISTA BRASILEIRO}

A publicidade comportamental tem uma estreita relação com práticas que muitas vezes violam a intimidade e a vida privada do consumidor, valores consagrados como direitos fundamentais pela Constituição Federal (artigo $5^{\circ}$, inciso X) ${ }^{33}$. Uma forma de não se atentar contra os referidos valores é se utilizar de procedimentos de anonimização e pseudonimização ${ }^{34}$.

A coleta de dados deve ser realizada através de mecanismos tecnológicos que sejam menos invasivos possíveis, de forma que sejam captadas somente as informações que sejam aptas a identificar os hábitos comportamentais do consumidor, sem violar a sua vida privada e intimidade. Deste modo, busca-se repelir a coleta de dados sensíveis relacionados à personalidade (v.g., origem, convicção religiosa, orientação sexual etc.) ou informações de segurança (v.g., senhas pessoais) ${ }^{35}$ dos consumidores.

Todo o procedimento de captação de dados deve ser feito através de meios lícitos, esclarecendo os consumidores a respeito da existência da referida coleta de informações, especificando as possíveis formas de utilização dos dados captados (que devem ser para fins

\footnotetext{
${ }^{31}$ FEDERAL TRADE COMISSION STAFF REPORT. Protecting consumer privacy in an era of rapid change: recommendations for businesses and policymakers. 2012, p. i. Disponível em: <https:/www.ftc.gov/sites/default/files/documents/reports/federal-trade-commission-report-protectingconsumer-privacy-era-rapid-change-recommendations/120326privacyreport.pdf>. Acesso em: 9 mar. 2015.

32 THOMAS, Liisa M. We know where you've been: emerging rules in online behavioral advertising. In: The computer \& Internet lawyer [1531-4944] Thomas Liisa, 2013, v. 30, no. 2 p. 18.

${ }^{33}$ Art. $5^{\circ}, \mathrm{X}$ - são invioláveis a intimidade, a vida privada, a honra e a imagem das pessoas, assegurado o direito a indenização pelo dano material ou moral decorrente de sua violação.

${ }^{34}$ MENDES, Laura Schertel. Privacidade, proteção de dados e defesa do consumidor: linhas gerais de um novo direito fundamental. São Paulo: Saraiva, 2014, p. 226.

35 Ibid., p. 226.
} 
socialmente aceitos) ${ }^{36}$, e mais importante, garantindo aos consumidores o direito de escolha. Quando este não é respeitado tem-se uma ofensa ao direito básico (liberdade de escolha) previsto no artigo $6^{\circ}$, inciso II do Código de Defesa do Consumidor ${ }^{37}$.

A depender da forma como seja realizada a publicidade comportamental pode configurar afronta ao artigo $6^{\circ}$, inciso IV do referido Código ${ }^{38}$, tanto quando expõe o consumidor de maneira compulsória a anúncios publicitários em sites que não mantém qualquer espécie de relação direta entre si (método coercitivo), como quando não dá ciência ao consumidor de que seus hábitos comportamentais estão sendo coletados para fins de publicidade (método desleal).

Segundo o disposto no artigo $7^{\circ}$, caput do Código de Defesa do Consumidor ${ }^{39}$, os direitos previstos no mesmo não excluem outros consagrados por diplomas normativos diversos. Por conseguinte, a proteção da privacidade e dos dados pessoais, consagrados como princípios do uso da internet no Brasil pelos incisos II e III do artigo $3^{\circ}$ da Lei Federal $n^{\circ}$ 12.965/2014 (Marco Civil da Internet) ${ }^{40}$, são também considerados direitos básicos dos consumidores.

O conceito de publicidade abusiva é construído a partir das diretrizes definidas no artigo 37, $§ 2^{\circ}$ do Código de Defesa do Consumidor ${ }^{41}$. Ao utilizar a expressão “dentre outras", o legislador instituiu um rol meramente exemplificativo (numerus apertus) ${ }^{42}$, e não taxativo ou exaustivo (numerus clausus), no que tange às espécies de publicidade que podem ser consideradas abusivas. Sendo assim, isso permite a conclusão de que caso haja violação de qualquer das normas que fazem parte do microssistema consumerista no contexto da efetivação da publicidade comportamental, esta poderá ser considerada como espécie de publicidade

\footnotetext{
${ }^{36}$ DELPIAZZO, Carlos E. Leciones de derecho telemático. Montevideo: Fundación de Cultura Universitaria, 2009 , t. I, p. $75-76$.

37 Art. $6^{\circ}$ [...] II - a educação e divulgação sobre o consumo adequado dos produtos e serviços, asseguradas a liberdade de escolha e a igualdade nas contratações.

${ }^{38}$ Art. $6^{\circ}$ [...] IV - a proteção contra a publicidade enganosa e abusiva, métodos comerciais coercitivos ou desleais, bem como contra práticas e cláusulas abusivas ou impostas no fornecimento de produtos e serviços.

39 Art. $7^{\circ}$. Os direitos previstos neste código não excluem outros decorrentes de tratados ou convenções internacionais de que o Brasil seja signatário, da legislação interna ordinária, de regulamentos expedidos pelas autoridades administrativas competentes, bem como dos que derivem dos princípios gerais do direito, analogia, costumes e equidade.

${ }^{40}$ Art. $3^{\circ}$. A disciplina do uso da internet no Brasil tem os seguintes princípios: [...] II - proteção da privacidade; III - proteção dos dados pessoais, na forma da lei.

${ }^{41}$ Art. $37, \S 2^{\circ}$. É abusiva, dentre outras a publicidade discriminatória de qualquer natureza, a que incite à violência, explore o medo ou a superstição, se aproveite da deficiência de julgamento e experiência da criança, desrespeita valores ambientais, ou que seja capaz de induzir o consumidor a se comportar de forma prejudicial ou perigosa à sua saúde ou segurança.

${ }^{42}$ FERNANDES NETO, Guilherme. Abuso do direito no Código de Defesa do Consumidor: cláusulas, práticas e publicidades abusivas. Brasília: Brasília Jurídica, 1999, p. 181.
} 
abusiva, e consequentemente, por se tratar de uma prática ilícita, sujeitar-se à responsabilização civil, penal e administrativa.

Assim, embora não haja no microssistema consumerista brasileiro regulamentação expressa acerca da publicidade comportamental a mesma poderá ser regulada pelo Poder Judiciário, Ministério Público, PROCONs e órgãos de autorregulamentação (v.g., Conselho Nacional de Autorregulamentação Publicitária - CONAR). Sempre serão bem-vindas atuações no sentido de proteger o consumidor com fundamento em qualquer dos princípios que fazem parte do microssistema consumerista, a exemplo do princípio da não-abusividade da publicidade, que se encontra positivado no artigo 37, caput do Código de Defesa do Consumidor ${ }^{43}$.

\section{CONCLUSÃO}

O conceito de publicidade pode ser entendido considerando esta como uma prática comercial de marketing, desenvolvida mediante uma comunicação comercial, que apresenta uma oferta destinada à divulgação, com finalidade econômica, de determinado produto, serviço, marca ou empresa, no escopo de persuadir consumidores, direta ou indiretamente, provocando ou aumentando a demanda em relação ao objeto do anúncio. Os principais personagens que participam da efetivação da publicidade são: o anunciante, o agente publicitário (ou agência publicitária) e o veículo de divulgação.

O apanágio que difere o instituto da publicidade em relação à propaganda é justamente a exploração de atividade econômica ou finalidade comercial, que se encontra presente naquela e ausente nesta.

Na seara que diz respeito à comunicação publicitária foram consagrados pelo Código de Proteção e Defesa do Consumidor os seguintes princípios: princípio da identificação da publicidade, princípio da obrigatoriedade do cumprimento, princípio da veracidade da publicidade, princípio da não-abusividade da publicidade, princípio da inversão do ônus da prova, princípio da transparência da fundamentação da publicidade, princípio da correção do desvio publicitário, e princípio da lealdade publicitária.

Quando exposto à publicidade comportamental o consumidor se mostra ainda mais vulnerável em relação aos fornecedores do que normalmente acontece nas outras espécies publicitárias. Isso porque, além de geralmente não poder escolher se os seus dados poderão ou

\footnotetext{
${ }^{43}$ Art. 37. É proibida toda publicidade enganosa ou abusiva.
} 
não ser organizados e utilizados para subsidiar esse tipo de publicidade, o mesmo não tem ciência de que isso acontece independente de sua vontade ou conhecimento.

A publicidade comportamental (behavioral advertising) consiste em um processo de segmentação de mercado que é realizado mediante o direcionamento de mensagens publicitárias especificamente desenvolvidas para um determinado público alvo (consumidor), partindo de um conjunto de informações que constituem o seu histórico de comportamento.

Geralmente desenvolvida na internet (online) a publicidade comportamental se utiliza de um critério de contextualização (variando de acordo com o conteúdo do site acessado) e/ou personalização (quando é direcionada em consonância com características pessoas de cada público consumidor). Neste último caso, o anúncio publicitário é elaborado com base em um perfil criado para cada consumidor (profiling) de acordo com seus hábitos de navegação.

A publicidade comportamental pode se manifestar por meio do remarketing, quando os anunciantes direcionam peças publicitárias aos consumidores de acordo, v.g., com seu histórico de navegação (sites visitados); da personalização na rede (web personalization), quando o anúncio publicitário é direcionado aos consumidores considerando seus interesses e preferências pessoais; e da personalização do negócio (deal customization), v.g., quando o fornecedor oferece um desconto a um determinado consumidor que visualizou um determinado produto no site mas não chegou a concluir a compra.

Apesar de existirem iniciativas tanto na União Europeia, com a Interactive Advertising Bureau (IAB), como nos Estados Unidos, através da Federal Trade Comission (FTC), a regulamentação da espécie publicitária em comento ainda se encontra apenas na seara principiológica.

Entretanto, não resta dúvida de que o consumidor deve tanto ter o direito de escolher se suas informações poderão ou não ser utilizadas para fins de publicidade comportamental, bem como estar ciente de quanto estiver sendo alvo de um anúncio publicitário dessa natureza. Além disso, quando violar direitos como a intimidade e a vida privada, consagrados pela Constituição Federal (artigo $5^{\circ}$, inciso X), ou a proteção da privacidade e dados pessoais consagrada pelo artigo $3^{\circ}$, incisos II e III da Lei Federal no 12.965/2014 (Marco Civil da Internet), a publicidade comportamental configurará hipótese de publicidade abusiva, nos termos do artigo $37, \S 2^{\circ}$ do Código de Defesa do Consumidor.

Uma vez considerada prática abusiva o fornecedor-anunciante, bem como os demais partícipes da veiculação da peça (somente em caso de agirem com dolo ou culpa lato sensu) poderão ser responsabilizados perante o Poder Judiciário, PROCONs, Ministério Público e o CONAR. 


\section{REFERÊNCIAS}

ABRAMS, Martin. Boxing and concepts of harm. In: Privacy and Data Security Law Journal, set. 2009.

ALVES, Fabrício Germano. Proteção constitucional do consumidor no âmbito da regulação publicitária. Natal: Espaço Internacional do Livro, 2013.

AMARAL JÚNIOR, Alberto do. O princípio da vinculação da mensagem publicitária. In: Revista de direito do consumidor. São Paulo: Revista dos Tribunais, v. 14, 1995.

BRASIL. Lei Federal $n^{\circ}$ 8.078, de 11 de setembro de 1990. Dispõe sobre a proteção do consumidor e dá outras providências.

Lei Federal $n^{\circ} 12.965$, de 23 de abril de 2014. Estabelece princípios, garantias, direitos e deveres para o uso da Internet no Brasil.

CLARK, Erick. La publicidad y su poder: las técnicas de provocación al consumo. Barcelona: Planeta, 1989.

CLINE, Kelly M.; COX, Jeffrey T. Parsing the demographic: the challenge of balancing online behavioral advertising and consumer privacy considerations. In: Journal of Internet law [1094-2904] Cox, Jeffrey, 2012 v.15, no. 9, p. 3.

CRANOR, Lorrie Faith. Can Users Control Online Behavioral Advertising Effectively? In: IEEE Security \& Privacy [1540-7993] Cranor, Lf, 2012 v. 10, no. 2 p. 93-96.

CUNHA, Belinda Pereira da. Antecipação da tutela no Código de Defesa do Consumidor. São Paulo: Saraiva, 1999.

DELPIAZZO, Carlos E. Leciones de derecho telemático. Montevideo: Fundación de Cultura Universitaria, 2009, t. I.

DIAS, Lucia Ancona Lopez de Magalhães. Publicidade e direito. São Paulo: Revista dos Tribunais, 2010.

Directiva 84/450/CEE. Disponível em: < http://eur-

lex.europa.eu/smartapi/cgi/sga_doc?smartapi!celexapi!

prod!CELEXnumdoc\&lg=PT\&numdoc=384L0450\&model=guichett_> Acesso em: 23 ago. 2010.

ESCOLA NACIONAL DE DEFESA DO CONSUMIDOR (Danilo Doneda). A proteção de dados pessoais nas relações de consumo: para além da informação creditícia. Brasília:

SDE/DPDC, 2010.

FEDERAL TRADE COMISSION STAFF REPORT. Online Behavioral Advertising: Moving the Discussion Forward to Possible Self-Regulatory Principles. Disponível em: $<$ https://www.ftc.gov/sites/default/files/documents/public_statements/online-behavioraladvertising-moving-discussion-forward-possible-self-regulatory-

principles/p859900stmt.pdf>. Acesso em: 9 mar. 2015. 
FEDERAL TRADE COMISSION STAFF REPORT. Protecting consumer privacy in an era of rapid change: recommendations for businesses and policymakers. 2012. Disponível em: $<$ https://www.ftc.gov/sites/default/files/documents/reports/federal-trade-commission-reportprotecting-consumer-privacy-era-rapid-change-recommendations/120326privacyreport.pdf> . Acesso em: 9 mar. 2015.

FEDERAL TRADE COMISSION STAFF REPORT. Self-Regulatory Principles For Online Behavioral Advertising: Behavioral Advertising Tracking, Targeting, \& Technology. February 2009. Disponível em:

$<$ http://www.ftc.gov/sites/default/files/documents/reports/federal-trade-commission-staffreport-self-regulatory-principles-online-behavioral-advertising/p085400behavadreport.pdf $>$. Acesso em: 3 mar. 2015.

FERNANDES NETO, Guilherme. Abuso do direito no Código de Defesa do Consumidor: cláusulas, práticas e publicidades abusivas. Brasília: Brasília Jurídica, 1999.

GALEANO, Eduardo. De pernas pro ar: a escola do mundo ao avesso. Tradução de Sérgio Faraco. 9. Ed. Porto Alegre: L\&PM, 2007.

IAB EUROPE. IAB Europe EU Framework for Online Behavioural Advertising. Disponível em: <http://www.iabeurope.eu/files/5013/8487/2916/2013-11-

11_IAB_Europe_OBA_Framework.pdf>. Acesso em: 3 mar. 2015.

LEÓN ARCE, Alicia de; MORENO-LUQUE CASARIEGO, Carmen; AZA CONEJO, M ${ }^{\mathrm{a}}$ Jesus. Derecho de consumo. Barcelona: Forum, 1995.

MARQUES, Cláudia Lima. Contratos no código de defesa do consumidor: o novo regime das relações contratuais. 4. Ed. São Paulo: Revista dos Tribunais, 2004.

MARTÍNEZ MARTÍNEZ, Ricard. Protección de datos personales y redes sociales: un cambio de paradigma. In: RALLO LOMBARTE, Artemi; MARTÍNEZ MARTÍNEZ, Ricard (Coord.). Derecho y redes sociales. 2. ed. Navarra: Aranzadi, 2013.

MENDES, Laura Schertel. Privacidade, proteção de dados e defesa do consumidor: linhas gerais de um novo direito fundamental. São Paulo: Saraiva, 2014.

OLEAGA, Ricardo. Aportación consumerista a la publicidade. In: La publicidade desde el consumidor. Bizkaia: Eroski Libros, 1991.

REYES LÓPEZ, María José. Manual de derecho de consumo. Madrid: La Ley, 2009.

SANTAELLA LÓPEZ, Manuel. El nuevo derecho de la publicidad. Madrid: Civitas, 1992.

SCHERKERKEWITZ, Isso Chaitz. Direito e internet. São Paulo: Revista dos Tribunais, 2014.

SMITH, Mike. Targeted: how technology is revolutionizing advertising and the way companies reach consumers. New York: AMACOM, 2015. 
TAYLOR, Gabriela. Advertising in a digital age: best practices \& tips for paid search and social media advertising. Lexington: Global \& Digital, 2013.

THOMAS, Liisa M. We know where you've been: emerging rules in online behavioral advertising. In: The computer \& Internet lawyer [1531-4944] Thomas Liisa, 2013, v. 30, no. 2 p. 16-19.

TUCKER, Avi Goldfarb and Catherine E. Economic and Business Dimensions Online Advertising, Behavioral Targeting, and Privacy. In: Communications of the ACM [00010782] Goldfarb, A, 2011, v. 54, no. 5, p. 25-27. 